\section{Tono-Pen tonometer and corneal thickness}

a strain gauge that is activated once it touches the cornea. Since the Tono-Pen indents a smaller surface area $\left(2.36 \mathrm{~mm}^{2}\right)$ of the cornea than does the Goldmann tonometer $\left(7.35 \mathrm{~mm}^{2}\right)$, the effects of corneal rigidity and surface tension of tears would be less significant. It is also known that different parts of the cornea have different thicknesses. This clinical study aimed to investigate whether the Tono-Pen would provide reliable and similar IOP readings when used at different sites on the cornea.

\section{Methods}

After full informed consent had been obtained from all subjects, 48 eyes of 48 subjects were enrolled in the study at the Queen Mary Hospital Ophthalmology Clinic, Hong Kong. All subjects had no corneal diseases and no astigmatism greater than 1.5 dioptre cylinder. Since the Tono-Pen readings were not open to interpretation, Goldmann tonometry was first carried out by an optometrist (K.H.M.). Four consecutive Goldmann measurements were made on each subject. Then, using the Tono-Pen XL (Mentor), two sets of IOP measurements (one on the central cornea and the other at the mid-periphery on the temporal side) were obtained from each patient by another optometrist (C.S.L.W.). The Ton-Pen tonometer was calibrated according to the manufacturer's instructions each day. Only the readings of the highest reliability were accepted (SEM $\leqslant 5 \%$ of the average); where the SEM was greater than $5 \%$ of the average the results were discarded and the measurement repeated. The two observers were each masked to the measurements by the other. The thickness of the cornea was then measured with an ultrasonic pachymeter (BVI, France), and its curvature with an auto-kerato-refractometer (KR-3100, Topcon, Japan).

\section{Results}

The Goldmann tonometer is most accurate when applied to a central corneal thickness of $520 \mu \mathrm{m}$, and the Perkins tonometer to a thickness of about $550 \mu \mathrm{m} .^{7}$ Therefore the collection and interpretation of data in this study were restricted to central corneal thicknesses ranging from 510 to $570 \mu \mathrm{m}$.
K.H. Mok

C.S.-L. Wong

V.W.-H. Lee

Queen Mary Hospital Unit Department of

Ophthalmology and Visual Sciences

The Chinese University of Hong Kong Hong Kong, China

Kwok Hei Mok, MPhil Ophthalmology

Department, K20N Queen Mary Hospital Pokfulam Road Hong Kong, China

Tel: (+852) 28553612 Fax: (852) 28554737 e-mail: mokkh@ha.org.hk

The authors have no direct or indirect proprietary interests in the Tono-Pen tonometer

Received: 14 July 1998 Accepted in revised form: 25 November 1998 
Table 1. Corneal thickness and IOP measured by Goldmann and Tono-Pen tonometers at the central and mid-peripheral cornea $(\mathrm{n}=48)$

\begin{tabular}{|c|c|c|c|}
\hline Corneal location: & \multicolumn{2}{|c|}{ Central } & Mid-peripheral \\
\hline \multicolumn{4}{|l|}{ Thickness $(\mu \mathrm{M})$} \\
\hline Mean $\pm S D$ & \multirow{2}{*}{\multicolumn{2}{|c|}{$\begin{array}{c}538 \pm 29 \\
511-568\end{array}$}} & $578 \pm 25$ \\
\hline Range & & & $525-628$ \\
\hline Tonometer: & Goldmann & Tono-Pen & Tono-Pen \\
\hline \multicolumn{4}{|l|}{ IOP (mmHg) } \\
\hline Mean $\pm S D$ & $15.7 \pm 3.1$ & $15.2 \pm 3.2$ & $15.7 \pm 3.3$ \\
\hline Range & $9-22$ & $7-22$ & $8-24$ \\
\hline
\end{tabular}

No statistically significant difference in the mean IOP readings was observed between the Goldmann and Tono-Pen tonometers (paired Student's $t$-test, $p>0.05$ ) (Table 1). The temporal mid-peripheral corneal thickness was significantly higher than the central thickness $(p<0.001)$. The mean IOP at the temporal mid-peripheral cornea was statistically higher $(p=0.02)$ than that at the central cornea as measured by the Tono-Pen, and the mean absolute difference was $1.2 \pm 0.8 \mathrm{mmHg}$. The correlation coefficient $(R)$ of the IOP readings measured by Tono-Pen at the central and temporal mid-peripheral cornea was $0.91(p<0.001)$ (Fig. 1).

\section{Discussion}

Goldmann applanation tonometer has long been regarded as the clinical gold standard in IOP measurement. The Tono-Pen tonometer measures IOP in a similar fashion to the Goldmann tonometer. Some studies, however, have found that the Tono-Pen underestimated IOP readings in the higher ranges ${ }^{8}$ and overestimated IOP in the lower ranges. ${ }^{9,10}$ Nevertheless, most studies generally agree that there is good correlation between the Goldmann and Tono-Pen tonometers, especially within the normal range of IOP. ${ }^{9,11-13}$ It has also been reported that there is good correlation between IOP measurements with the TonoPen and manometric readings in human autopsy eyes. ${ }^{11}$

The Tono-Pen is a versatile, portable, electronic applanation tonometer. It is especially useful in infants and young children when slit-lamp examination is difficult. Due to the poor fixation of these patients, it is not always easy to place the small tip of the Tono-Pen accurately over the central cornea. Eccentric applanation is also useful in patients with central corneal irregularities, such as scarring and deformation. A study ${ }^{14}$ has compared the IOP measured by the TonoPen at different corneal locations of cadaveric eyes. The

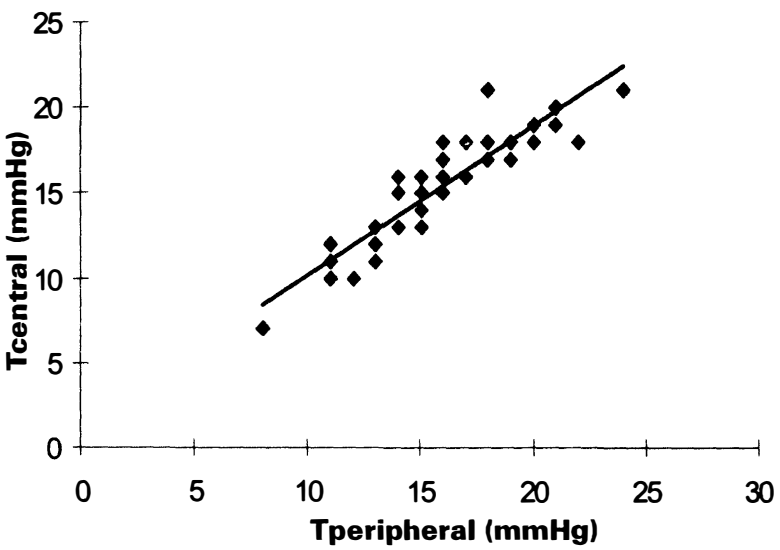

Fig. 1. Scattergram and linear regression for Tono-Pen IOP measured at the central cornea (Tcentral) and the mid-peripheral cornea (Tperipheral). Regression line: $\mathrm{y}=1.50 \mathrm{x}+0.87 ; \mathrm{r}=0.91, \mathrm{p}<0.001$.

investigators found that the mean IOP at the midperiphery or the clear limbal cornea was not significantly different from the IOP at the central cornea, indicating that a non-central corneal IOP reading could be as accurate as a central measurement. However, this in vitro study is flawed in that cadaveric eyes do not have physiological variables present in living eyes, such as pre-corneal tear film, a viable corneal epithelium and endothelium, normal corneal thickness and rigidity. The present study aimed to compare the IOP readings taken by the Tono-Pen at two different corneal locations (central and mid-peripheral) of living eyes. Midperipheral IOP was highly correlated with the central readings, and about $70 \%$ of paired differences were within $\pm 1 \mathrm{mmHg}$. Our results suggest that the Tono-Pen gives reliable IOP readings at both the central and the peripheral cornea.

Several studies ${ }^{2-4}$ have shown that the corneal thickness in ocular hypertensive eyes is significantly greater than normal (Table 2). Ehlers and associates ${ }^{7}$ extrapolated from this that the Goldmann tonometer overestimates or underestimates IOP by about $5 \mathrm{mmHg}$ for every $70 \mu \mathrm{m}$ increase in central corneal thickness, and Wolfs and associates ${ }^{4}$ showed an increase of $0.19 \mathrm{mmHg}$ in IOP for each $10 \mu \mathrm{m}$ increase in thickness. A significant number of hypertensive patients have normal IOP if corneal thickness is taken into account. ${ }^{3}$ On the other hand, low-tension glaucomatous patients with a thinner cornea may have a higher IOP if their corneal thickness is also considered. In the present study, although the mean mid-peripheral thickness was significantly higher than the central thickness, only about a $1 \mathrm{mmHg}$ difference in

Table 2. The effect of corneal thickness on IOP measurements

\begin{tabular}{|c|c|c|c|c|c|c|c|c|}
\hline & \multicolumn{2}{|c|}{ Argus $^{1}(1995)$} & \multicolumn{2}{|c|}{ Herndon et al. ${ }^{3}$ (1997) } & \multicolumn{2}{|c|}{ Wolfs et al. ${ }^{4}$ (1997) } & \multicolumn{2}{|c|}{ Present study } \\
\hline Tonometer: & \multicolumn{2}{|c|}{ Goldmann } & \multicolumn{2}{|c|}{ Goldmann } & \multicolumn{2}{|c|}{ Goldmann } & \multicolumn{2}{|c|}{ Tono-Pen } \\
\hline Subjects: & Normal & $\mathrm{OH}$ & Normal & $\mathrm{OH}$ & Normal & $\mathrm{OH}$ & \multicolumn{2}{|c|}{ Normal } \\
\hline Location: & \multicolumn{2}{|c|}{ Central } & \multicolumn{2}{|c|}{ Central } & \multicolumn{2}{|c|}{ Central } & Central & Mid-peripheral \\
\hline Thickness $(\mu \mathrm{m})$ & 567 & 610 & 561 & 606 & 537 & 553 & 538 & 578 \\
\hline Difference $(\mu \mathrm{m})$ & \multicolumn{2}{|c|}{43} & \multicolumn{2}{|c|}{45} & \multicolumn{2}{|c|}{16} & \multicolumn{2}{|r|}{40} \\
\hline IOP (mmHg) & 15.5 & 23.2 & 13.2 & 21.5 & 14.6 & 18.7 & 15.2 & 15.7 \\
\hline Difference $(\mathrm{mmHg})$ & \multicolumn{2}{|c|}{7.7} & \multicolumn{2}{|c|}{8.3} & \multicolumn{2}{|c|}{4.1} & \multicolumn{2}{|r|}{0.5} \\
\hline
\end{tabular}

$\mathrm{OH}$, ocular hypertension. 
IOP was observed (Table 2) with the Tono-Pen tonometer. The Tono-Pen tonometer appeared to be less affected by corneal thickness than the Goldmann tonometer, mainly because the Tono-Pen indents a relatively smaller surface area than does the Goldmann tonometer $\left(2.36 \mathrm{~mm}^{2}\right.$ vs $\left.7.35 \mathrm{~mm}^{2}\right)$. Our results suggest that the Tono-Pen tonometer might give a more accurate IOP for individuals with a cornea thicker or thinner than normal.

The authors thank Dr David Ho Yin Chan for proofreading this article.

\section{References}

1. Argus WA. Ocular hypertension and central corneal thickness. Ophthalmology 1995;102:1810-12.

2. Whitacre MM, Richard AS, Hassanein K. The effect of corneal thickness on applanation tonometry. Am J Ophthalmol 1993;115:592-6.

3. Herndon LW, Choudhri SA, Cox T, Damji KF, Shields MB, Allingham R. Central corneal thickness in normal, glaucomatous, and ocular hypertensive eyes. Arch Ophthalmol 1997;115:1137-41.

4. Wolfs RCW, Klaver CCW, Vingerling JR, Grobbee DE, Hofman A, Dejong PTVM. Distribution of central corneal thickness and its association with intraocular pressure: the Rotterdam study. Am J Ophthalmol 1997;123:767-72.

5. Chatterjee A, Shah S, Bessant DA, Naroo SA, Doyle SJ. Reduction in intraocular pressure after excimer laser photorefractive keratectomy. Ophthalmology 1997;104:355-9.
6. Foster PJ, Bassanhu J, Alsbirk PH, Munkhbayar D, Uranchimeg D, Johnson GJ. Central corneal thickness and intraocular pressure in a Mongolian population. Ophthalmology 1998;105:969-73.

7. Ehlers N, Bramsen T, Sperling S. Applanation tonometry and central corneal thickness. Acta Ophthalmol (Copenh) 1975;53:34-43.

8. Kooner KS, Cooksey JC, Barron JB, Zimmerman TJ, Gupte RK, Wall JL. Tonometry comparison: Goldmann versus Tono-Pen. Ann Ophthalmol 1992;24:29-36.

9. Frenkel RE, Hong YJ, Shin DH. Comparison of the Tono-Pen to the Goldmann applanation tonometer. Arch Ophthalmol 1988;106:750-3.

10. Kao SF, Lichter PR, Bergstrom TJ, Rowe S, Musch DC. Clinical comparison of the Oculab Tono Pen to the Goldmann applanation tonometer. Ophthalmology 1987;94:1541-4.

11. Boothe WA. The Ton-Pen: a manometric and clinical study. Arch Ophthalmol 1988;106:1214-7.

12. Hessemer V, Rosler R, Jacobi KW. Comparison of intraocular pressure measurements with the Oculab Tono-Pen vs manometry in humans shortly after death. Am J Ophthalmol 1988;105:678-82.

13. Minckler DS, Baerveldt G, Heuer DK, Quillen-Thomas B, Walonker AF, Weiner J. Clinical evaluation of the Oculab Tono-Pen. Am J Ophthalmol 1987;104:168-73.

14. Khan JA, Davis M, Graham CE, Trank J, Whitacre MM. Comparison of Oculab Tono-Pen readings obtained from various corneal and scleral locations. Arch Ophthalmol 1991;109:1444-6. 